\title{
Pengaruh Kualitas Produk Dan Promosi Terhadap Keputusan Pembelian (Studi Kasus pada Usaha Dagang Keripik Buah "Mekar Sari" di Desa Tlogo III, Kecamatan Kanigoro, Kabupaten Blitar)
}

\author{
The Effect of The Quality Products and Promotion Towards The Purchase \\ Decisions (Case Study In "Mekar Sari" Fruit Trading Business \\ in the Tlogo III Village, Kanigoro Sub-District, Blitar District)
}

\author{
Riska Nindia Sari, ST., M.AB ${ }^{1}$, Wulan Destari Natalia ${ }^{2}$ \\ 1 Fakultas Ilmu Sosial dan Ilmu Politik, Univ. Islam Balitar \\ Jl. Majapahit No. 2 - 4, Blitar, Indonesia \\ 2 Fakultas Ilmu Sosial dan Ilmu Politik, Univ. Islam Balitar \\ Jl. Majapahit No. 2 - 4, Blitar, Indonesia \\ E-mail: Riskanindya@gmail.com
}

\begin{abstract}
ABSTRAK
Usaha dagang mampu memenangkan persaingan jika dapat memiliki produk sesuai dengan keinginan dan kebutuhan pelanggan serta dapat menyampaikan kelebihan-kelebihan produknya kepada konsumen. Terdapat beberapa aspek yang dapat mempengaruhi pengambilan keputusan konsumen untuk membeli produk, diantaranya adalah produk yang berkualitas dan kegiatan promosi perusahaan. Penelitian ini dilakukan pada Usaha Dagang Keripik Buah "Mekar Sari” di Dd. Tlogo III, Kec. Kanigoro, Kab. Blitar. Penelitian ini bermaksud untuk mengetahui pengaruh dari kualitas produk dan promosi terhadap keputusan pembelian. Pendekatan yang digunakan adalah dengan metode penelitian kuantitatif menggunakan kuisioner. Populasi yang digunakan adalah konsumen pada Usaha Dagang Keripik Buah "Mekar Sari. Sedangkan untuk menganalisi datanya digunakan uji validitas menggunakan product moment, dan Croncbach's Alpha sebagai pengujian reliabilitas. Untuk pengujian analisis prasyarat digunakan pengujian normalitas dan uji heteroskedastisitas. Kemudian pada pengujian terhadap hipotesa digunakan uji parsial T. Hasil penelitian ini diperoleh berdasarkan perhitungan uji $\mathrm{T}$ dengan koefisien nilai sig. dari kualitas produk terhadap keputusan pembelian menghasilkan nilai $0,000<0.05$ yang memiliki arti semakin meningkatnya kualitas produk menyebakan peningkatan tehadap keputusan pembelian. Dan nilai sig. promosi terhadap keputusan pembelian menghasilkan angka $0,003<0,05$ yang berarti semakin baik promosinya akan semakin baik keputusan pembelian.
\end{abstract}

Kata Kunci : kualitas produk, keputusan pembelian, promosi.

\section{ABSTRACT}

Trading business is able to win the competition if it can have products according to customer wants and needs and can convey the advantages of its products to consumers. There are several aspects that can influence consumer decision making to buy products, including quality products and company 
promotion activities. This exploration was directed at the "Mekar Sari" Fruit Chips Trading Business in Dd. Tlogo III, Kec. Kanigoro, Kab. Blitar. This examination means to decide the impact of item quality and promotion on purchasing decisions. The methodology utilized is a quantitative research method using a questionnaire. The population used is the consumer in Mekar Sari Fruit Chips Trading Business. Meanwhile, to analyze the data used the validity test using the product moment, and Croncbach's Alpha as a reliability test. To test the prerequisite analysis used normality testing and heteroscedasticity test. Then in testing the hypothesis the $T$ partial test is used. The consequences of this examination were gotten dependent on the calculation of the $T$ test with the coefficient of sig. From product quality to purchasing decisions, it produces a value of $0.000<0.05$, which means that the increasing quality of the product causes an increase in purchasing decisions. And the sig. promotion of purchasing decisions produces a number of $0.003<0.05$, which implies that the better the promotion, the better the purchasing decision.

Keywords: product quality, purchase decisions, promotions.

\section{PENDAHULUAN}

Semakin banyak dan bertambah jumlah kebutuhan masyarakat terhadap produk yang berkualitas, maka mengakibatkan terjadinya persaingan bisnis, sehingga menjadikan pemasaran menjadi faktor yang sangat penting. Perusahaan harus dapat melakukan pemasaran jasa ataupun barang yang ditawarkan pada customer agar mampu bertahan serta mampu bersaing dengan kompetitor. Kotler \& Amstrong (2001:354) menyatakan bahwa senjata strategis dan potensial dalam memenangkan persaingan adalah kualitas produk. Sehingga perusahaan dengan produk yang berikualitas akan mampu berkembang secara pesat, dan untuk rentang waktu yang lama dapat memiliki keberhasilan yang lebih baik dibandingkan dengan perusahaan lainya.

Dalam memproduksi produk alangkah baiknya perusahaan dapat menyesuaiakan dengan kebutuhan serta keinginan konsumen. Hal ini membuat produk mampu bersaing, sehingga konsumen menjadi semakin banyak alternatif yang dapat dipilih sebelum memutuskan terjadinya pembelian produk yang ditawarkan. Maka, peran promosi menjadi sangat penting dalam perusahaan. Melalui promosi perusahaan dapat menyampaikan informasi tentang produknya kepada konsumen. Dengan promosi konsumen dapat mengetahui informasi mengenai kelebihan-kelebihan sebuah produk, sehingga menarik pelanggan untuk dapat mencoba dan selanjutnya keputusan akan diambil untuk melakukan 
pembelian. Artinya dapat dikatakan bahwa promosi adalah aspek penting pada menajemen pemasaran, sebab melalui promosi akan membuat konsumen yang tadinya tidak tertarik dengan sebuah produk sehingga dapat dirubah pikiranya menjadi menginginkan dan membeli produk.

Dengan adanya promosi yang baik, komunikasi diantara perusahaan dan konsumen akan terjalin. Selanjutnya apabila komunikasi telah terjalin diharapkan perusahaan akan mendapatkan konsumen baru dan konsumen yang lama dapat bertahan. Tidak hanya itu perusahaan juga harus mampu memberikan kepuasan dan layanan yang menarik serta mampu memenuhi keinginan yang dibutuhkan konsumen. Layanan yang membuat konsumen puas akan menyebabkan pembelian yang berulang, hal ini akan menghasilkan peningkatan penjualan. Kepuasaan serta loyalitas konsumen dapat diciptakan melalui layanan yang baik, sehingga dapat membantu bersaing dengan kompetitor (Kotler, 1999:297). Ketidapusan terjadi apabila sebuah perusahaan tidak mampu memenuhi keinginan dan kebutuhan konsumen. Kepuasan dan ketidakpuasan konsumen biasanya dinilai dengan perbandingan kinerja atau hasil yang dirasakan terhadap harapan konsumen.

Untuk memudahkan dalam melakukan penelitian, maka disusun kerangka pemikiran. Berikut gambaran dari kerangka pemikiran dari fenomena yang akan diteliti.

Gambar 1. Kerangka Pemikiran Penelitian

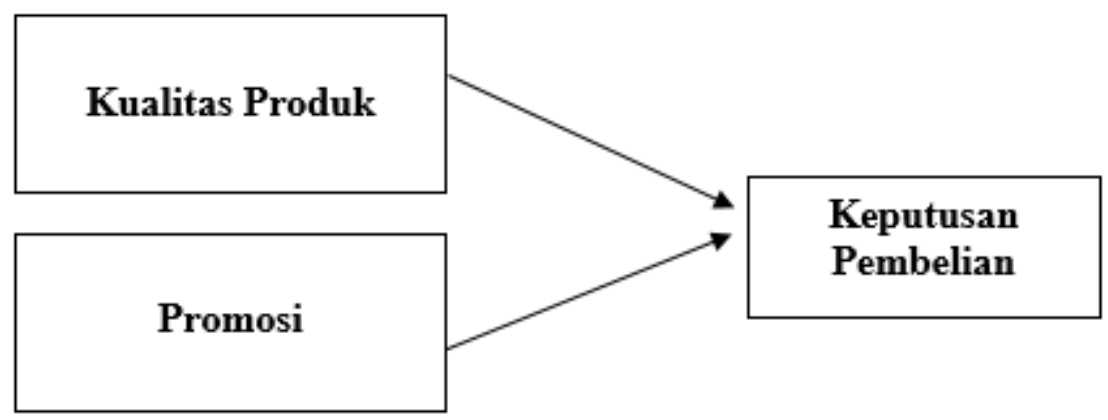

Dari kerangka pemikiran serta teori yang telah dikemukakan diatas maka rumusan hipotesa penelitian adalah:

$\mathrm{H}_{\mathrm{o}}$ : Diduga tidak ada pengaruh kualitas produk terhadap keputusan pembelian Keripik Buah "Mekar Sari" di Desa Tlogo III, Kecamatan Kanigoro, Kabupaten Blitar.

$\mathrm{H}_{\mathrm{a} 1}$ : Diduga terdapat pengaruh kualitas produk terhadap keputusan pembelian 
Keripik Buah "Mekar Sari" di Desa Tlogo III, Kecamatan Kanigoro, Kabupaten Blitar.

$\mathrm{H}_{\mathrm{o} 2}$ : Diduga tidak ada pengaruh promosi terhadap keputusan pembelian Keripik Buah Buah "Mekar Sari" di Desa Tlogo III, Kecamatan Kanigoro, Kabupaten Blitar.

$\mathrm{H}_{\mathrm{a} 2}$ : Diduga ada pengaruh promosi terhadap keputusan pembelian Keripik Buah Buah "Mekar Sari" di Desa Tlogo III, Kecamatan Kanigoro, Kabupaten Blitar.

\section{METODE PENELITIAN}

Pendekatan atau metode dalam penelitian ini digunakan pendekatan kuantitatif. Pendekatan penelitian kuantitatif merupakan penelitian ilmiah yang secara sistematis meneliti fenomena tertentu serta bagian dan hubunganya. Penelitian kuantitatif memiliki tujuan untuk mengunakan serta mengembangkan model yang matematis, teori serta hipotesa yang berkaitan dengan fenomena yang ada. Selain itu, penelitian kuantitatif bermaksud untuk menjelaskan sesuatu keadaan obyek tertentu berdasarkan hubungan ataupun pengaruh dari faktor lain serta menarik kesimpulan berdasarkan dari hasil perhitungan yang dikelola dengan statistik.

Dalam pengumpulan data, peneliti menggunakan metode survei. Survei biasanya digunakan untuk mengumpulkan data dari objek penelitian tertentu menggunakan angket atau kuesioner, test, maupun melalui wawancara (Sugiyono, 2015). Penelitian pada Keripik Buah "Mekar Sari” bertujuan agar diketahui pengaruh antara kualitas produk dan promosi terhadap keputusan pembelian pada usaha dagang.

Populasi yang digunakan adalah seluruh konsumen Keripik Buah "Mekar Sari” di Desa Tlogo, Kecamatan Kanigoro, Blitar sebanyak 120 orang. Untuk mengambil sampel digunakan teknik Simple Random Sampling. Pada teknik ini sampel didapatkan melalui proses acak sederhana dengan daftar bilangan random, tujuanya adalah agar masing-masing elemen pada populasi mendapatkan kesempatan yang sama untuk terpilih sehingga dapat digunakan sebagai sampel (J. Supranto, 2000). Rumus Slovin (1960) dalam Sevilla (1994) dapat digunakan 
untuk menentukan ukuran penetapan jumlah sampel pada populasi. Setelah menerapkan rumus Slovin maka didapatkan jumlah sampel yang akan dijadikan sebagai responden sebanyak 92.

Untuk analisis data digunakan beberapa teknik uji. Uji yang pertama adalah uji instrument dengan uji validitas dan reliabilitas. Berdasarkan Sugiyono (2014:363), validitas dapat diartikan sebagai tingkat ketepatan dari data yang terjadi pada sebuah objek yang diteliti dengan data yang peneliti laporkan. Sedangkan uji reliabilitas diartikan sebagai sebuah indeks untuk memperlihatkan sejauh mana hasil sebuah penelitian menggunakan pengukuran yang dapat dipercaya. Dipercaya atau reliable dari hasil pengukuran terjadi jika pada beberapa kali dilaksanakan pengukuran kepada sekelompok subyek yang sama, sepanjang aspek tersebut di ukur dalam sebuah subyek memang tidak berubah. Menurut Ghozali (2011) peniliaian terhadap realibilitas dapat menggunakan Cronbach Alpha. Jika nilai dari koefisien lebih besar dari signifikansinya $60 \%$ atau 0,6 maka butir angket yang digunakan reliable, tetapi apabila sebaliknya lebih kecil dari 0,6 angket yang digunakan dikatakan tidak reliable.

Uji berikutnya adalah uji asumsi klasik, diantaranya dengan uji normalitas dan Heteroskedastisitas. Uji normalitas merupakan pengujian untuk mengetahui apakah sebuah model regresi variabel residual mengalami distribusi normal atau tidak (Ghozali,2011). Untuk normalitas menggunakan pengujian KolmogrovSmirnov (K-S). Pada uji normalitas apabila nilai asymp.sig. > alpha 0.05 dapat dikatakan bahwa distribusinya normal, sebaliknya apabila asymp.sig. $<$ alpha 0.05 dinyatakan tidak terdistribusi normal (Ghozali,2011). Sedangkan untuk pengujian heteroskedastisitas bertujuan agar diketahui apakah pada model regresi terdapat ketidaksamaan varian antara pengamatan ke pengamatan lainya (Ghozali, 2005). Uji Glejser digunakan untuk deteksi adanya gejala heteroskedastisitas. Uji Glejser diterapkan dengan meregresikan residual dengan variable independen, dimana sebuah variabel dinyatakan tidak terdapat heteroskedastisitas jika didapatkan nilai signifikanya lebih besar dari 0.05 (Rochmat Aldy, 2017).

Uji yang terakhir adalah uji pengaruh parsial (Uji T). Sugiyono, (2008) menyebutkan uji pengarus parsial memiliki tujuan agar diketahui seberapa besar pengaruh setiap variabel independen diantaranya kualitas produk dan promosi 
secara individual (parsial) dengan variabel dependen keputusan pembelian. Uji ini dapat diamati melalui output dari aplikasi SPSS, apabila tabel sig < 0,05 maka variabel memiliki pengaruh secara signifikan.

\section{HASIL PENELITIAN DAN PEMBAHASAN}

\section{Uji Instrument}

Uji validitas digunakan untuk menggambarkan variabel kualitas produk, dan promosi (X), dan Keputusan Pembelian (Y). Pengukuran tingkat validitas dilakukan dengan dibandingkan anatara hasil $\mathrm{r}_{\text {hitung }}$ atau item total correlation dengan hasil $r_{\text {tabel }}$ untuk degree of freedom $(\mathrm{df})$ dapat dihitung dengan $=\mathrm{n}-\mathrm{k}$, untuk $\mathrm{n}$ merupakan jumlah dari sampel, sedangkan $\mathrm{k}$ merupakan jumlah variabel independenya. Untuk $r$ tabel dapat dinyatakan sebagai berikut (Ghozali, 2011) :

Apabila: $r_{\text {hitung }}>r_{\text {tabel }}$, artinya butir kuesioner yang digunakan valid Apabila: $r_{\text {hitung }}>r_{\text {tabel}}$, artinya butir kuesioner yang digunakan tidak valid.

Tabel 1. Hasil Uji Validitas Instrumen Variabel Produk

\begin{tabular}{|l|c|c|c|c|}
\hline \multicolumn{1}{|c|}{ Variabel } & $\begin{array}{c}\text { No } \\
\text { Item }\end{array}$ & $\mathrm{r}$ hitung & $\mathrm{r}$ tabel & Keterangan \\
\hline $\mathrm{X} 1$ & 1. & 0.777 & 0,2050 & Valid \\
\cline { 2 - 5 } (Kualitas Produk) & 2. & 0.737 & 0,2050 & Valid \\
\cline { 2 - 5 } & 3. & 0.532 & 0,2050 & Valid \\
\hline $\mathrm{X} 2$ & 1. & 0.812 & 0,2050 & Valid \\
\cline { 2 - 5 } (Promosi) & 2. & 0.836 & 0,2050 & Valid \\
\cline { 2 - 5 } & 3. & 0.802 & 0,2050 & Valid \\
\hline Y & 1. & 0.627 & 0,2050 & Valid \\
\cline { 2 - 5 } (Keputusan pembelian) & 2. & 0.824 & 0,2050 & Valid \\
\cline { 2 - 5 } & 3. & 0.783 & 0,2050 & Valid \\
\hline
\end{tabular}

Berdasarkan tabel 1 terlihat bahwa item yang mengukur variabel kualitas produk, promosi dan keputusan pembelian dari pernyataan-pertanyaan yang disajikan untuk diisi oleh responden pada kuesioner lebih besar dari hasil $r$ tabel yang memperoleh nilai 0,2050, sehingga instrumen dalam variabel produk dikatakan valid.

Selanjutnya, uji reliabilitas yang digunakan untuk melihat apakah sebuah kuisioner merupakan indikator dari variabel. Berikut ini hasi uji reliabilitas yang dilakukan: 
Tabel 2. Hasil Uji Reliabititas

\begin{tabular}{|c|l|c|c|c|}
\hline No & \multicolumn{1}{|c|}{ variabel } & $\begin{array}{l}\text { cronbach's } \\
\text { alpha }(\alpha)\end{array}$ & Alpha & Keterangan \\
\hline 1. & Produk & 0,723 & 0,060 & reliabilitas \\
\hline 2. & Promosi & 0,784 & 0,060 & reliabilitas \\
\hline 3. & Keputusan pembelian & 0,606 & 0,060 & reliabilitas \\
\hline
\end{tabular}

Dari uji tersebut (Tabel 2) menunjukkan hasil pada cronbach's alpha $(\alpha)$ lebih dari standar minimal yang menjadi persyaratan yaitu 0,060. Sehingga kesimpulanya adalah semua variabel produk, promosi, dan keputusan pembelian dikatakan reliable.

\section{Uji Asumsi Klasik}

Uji Kolmogrov-Smirnov (K-S) digunakan sebagai alat analisis pada penelitian ini. Probabilitas (Asymtotic Significance) digunakan sebagai dasar pengambilan keputusan. Pada uji ini jika hasil asymp.sig. > alpha 0.05 dapat dikatakan terdistribusi normal, tetapi apabila asymp.sig. < alpha 0.05 maka tidak terdistribusi normal (Ghozali,2011).

Tabel 3. Hasil Uji Normalitas

One-Sample Kolmogorov-Smirnov Test

\begin{tabular}{|ll|r|}
\hline & & $\begin{array}{c}\text { Unstandardized } \\
\text { Residual }\end{array}$ \\
\hline N & Mean & 92 \\
Mormal Parameters &, 0000000 \\
& Std. Deviation & 1,30276677 \\
& Absolute & 107 \\
Kolmogorov-Smirnov Z & Positive &, 107 \\
Asymp. Sig. (2-tailed) & Negative &,- 053 \\
a. Test distribution is Normal. & 1,025 \\
b. Calculated from data. &, 244 \\
\hline
\end{tabular}

Hasil diatas (Tabel 3) menunjukkan Kolmogrov-Smirnov menghasilkan nilai 1,025 dengan Sig. pada 0,244 atau lebih besar dari 0,05, sehingga bisa dinyatakan datanya telah memiliki distribusi normal.

Selanjutnya pengujian heteroskedastisitas dengan menerapkan uji glejser yang diimplementasikan melalui meregresikan antara absolut residual dengan variabel bebas. Apabila hasil dari signifikansi di seluruh variabel pada uji t sig. > 0,05, maka tidak ditemukan adanya heterokedastisitas atau varian residual homogen (Rochmat Aldy, 2017). 
Tabel 4.Hasil Uji Heteroskedastisitas

Coefficients $^{a}$

\begin{tabular}{|c|c|c|c|c|c|c|}
\hline \multirow{2}{*}{\multicolumn{2}{|c|}{ Model }} & \multicolumn{2}{|c|}{$\begin{array}{c}\text { Unstandardized } \\
\text { Coefficients }\end{array}$} & \multirow{2}{*}{$\begin{array}{c}\text { Standardized } \\
\text { Coefficients } \\
\text { Beta } \\
\end{array}$} & \multirow[b]{2}{*}{$\mathrm{t}$} & \multirow[b]{2}{*}{ Sig. } \\
\hline & & $\mathrm{B}$ & Std. Error & & & \\
\hline \multirow[t]{3}{*}{1} & (Constant) &, 762 & 813 & & ,938 &, 351 \\
\hline & KUALITAS PRODUK &, 020 &, 055 &, 041 &, 365 &, 716 \\
\hline & PROMOSI & &, 057 &, 010 & 091 &, 928 \\
\hline
\end{tabular}

a. Dependent Variable: Abs_Res

Dari tabel 4 dapat dilihat seluruh variabel indenpenden memiiki hasil sig. lebih dari 0,05 dengan under standardized residual, yaitu kualitas produk dengan nilai sig. sebesar 0,716, sedangkan promosi degan nilai 0,928. Sehingga, kesimpulanya adalah model regresi yang diajukan tidak terdapat heteroskedastisitas.

\section{Uji Hipotesis}

Sugiyono (2008), menyebutkan uji T memiliki tujuan agar diketahui besarnya pengaruh setiap variabel independen diantaranya kualitas produk dan promosi dengan individual (parsial) dengan variabel dependen keputusan untuk membeli. Uji ini dapat dilihat dari luaran SPSS berdasarkan pada tabel sig. $<0.05$, dapat dikatakan varibel memiliki pengaruh secara signifikan.

Tabel 5. Hasil pengujian Uji Pengaruh Parsial

\section{Coefficients $^{\mathrm{a}}$}

\begin{tabular}{|c|c|c|c|c|c|c|}
\hline \multirow{2}{*}{\multicolumn{2}{|c|}{ Model }} & \multicolumn{2}{|c|}{$\begin{array}{l}\text { Unstandardized } \\
\text { Coefficients }\end{array}$} & \multirow{2}{*}{$\begin{array}{c}\begin{array}{c}\text { Standardized } \\
\text { Coefficients }\end{array} \\
\text { Beta } \\
\end{array}$} & \multirow[b]{2}{*}{$\mathrm{t}$} & \multirow[b]{2}{*}{ Sig. } \\
\hline & & $\mathrm{B}$ & Std. Error & & & \\
\hline \multirow[t]{3}{*}{1} & (Constant) & 2,557 & 1,449 & & 1,764 &, 081 \\
\hline & $\begin{array}{l}\text { KUALITAS } \\
\text { PRODUK }\end{array}$ &, 478 &, 098 & ,441 & 4,882 &, 000 \\
\hline & PROMOSI & .308 & .101 & .275 & 3,046 & .003 \\
\hline
\end{tabular}

a. Dependent Variable: KEPUTUSAN PEMBELIAN

Dari tabel 5 dapat dijelaskan dengan analisis berikut:

a. Pengaruh variabel kualitas produk terhadap keputusan konsumen menunjukkan hasil signifikansi dengan nilai 0,000 lebih kecil dari taraf signifikanya yaitu 0,05 dengan nila $\mathrm{T}_{\text {hitung }}$ dengan nilai 4,882. Maka dapat ditarik kesimpulan bahwa $\mathrm{H}_{01}$ ditolak dan $\mathrm{H}_{\mathrm{a} 1}$ dapat diterima. Hal ini membuktikan bahwa kualitas produk memiliki pengaruh yang signifikan 
secara parsial terhadap keputusan untuk membeli pada Keripik Buah "Mekar Sari”. Hasil ini selaras dengan penelitian Dede Aprisal (2017) tentang "Pengaruh Kualitas Produk, Harga, Promosi, Dan Lokasi Terhadap Keputusan Pembelian (Studi Kasus Pada Great Store Clothing Samarinda)".

b. Promosi memiliki pengaruh secara signifikan dan positif terhadap keputusan pembelian yang terbukti dari nilai koefien sig. 0,003 > 0,05 dan hasil $\mathrm{T}_{\text {hitung }}$ $=3,046$. Sehingga kesimpulanya bahwa $\mathrm{H}_{02}$ ditolak dan $\mathrm{H}_{\mathrm{a} 2}$ diterima. Hal ini membuktikan bahwa promosi memiliki pengaruh yang besar terhadap keputusan untuk membeli pada Keripik Buah "Mekar Sari”. Hasil ini selaras dengan penelitian Yulihardi, SE, MM dan Yolamalinda, SE, M.Si (2013) tentang "Pengaruh Penetapan Harga dan Promosi Terhadap Keputusan Pembelian Sepeda Motor Merek Honda di Dharmawangsa"

\section{KESIMPULAN}

Dari analisis dan pembahasan yang telah dipaparkan sebelumnya, maka didapatkan kesimpulan diantaranya :

1) Terdapat pengaruh yang signifikan varibel kualitas produk terhadap keputusan pembelian pada keripik buah "Mekar Sari" di Desa Tlogo III, Kecamatan Kanigoro Kabupaten Blitar, dimana berdasarkan uji t diketahui bahwa niliai 0,000 lebih kecil dari taraf signifikansinya yaitu 0,05 dengan nila $T_{\text {hitung }}$ dengan nilai 4,882 .

2) Promosi berpengaruh sighnifikan terhadap keputusan pembelian keripik buah "Mekar Sari” di Desa Tlogo III, Kecamatan Kanigoro Kabupaten Blitar, ini dibuktikan dengan nilai uji t memperlihatkan bahwa koefien sig. 0,003 lebih besar 0,05 serta nilai $\mathrm{T}_{\text {hitung }}=3,046$.

Saran-saran yang dapat dijadikan bahan pertimbangan antara lain:

1) Untuk pemilik Usaha Keripik Buah "Mekar Sari"

Usaha Dagang Keripik Buah "Mekar Sari” dapat mempertahankan kualitas produk, dengan menjaga cita rasa produk, membuat kemasan yang menarik, dan pemberian layanan yang berdampak pada kepuasan konsumen serta tidak melakukan perubahan merek dagang atau nama produk yang memang telah 
dikenal oleh pembeli. Hal-hal tersebut adalah alternatif-alternatif yang dapat diterapkan. Perusahaan diharapkan mampu meningkatkan kegiatan promosi baik dengan kegiatan yang telah dilakukan maupun melakukan terobosan baru. Kegiatan yang dilakukan berkaitan dengan upaya agar produk dapat dikenal oleh konsumen agar konsumen membeli produk, sehingga menjadi berlangganan. Disamping itu upaya agar menumbuhkan loyalitas konsumen, maka perusahaan harus dapat menjaga produk tetap berkualitas produk sehingga konsumen menjadikan pilihan utama. Selanjutnya diharapkan perusahaan dapat menjaga kualitas dengan tetap memakai bahan baku dengan kualitas yang baik serta melakukan peningkatan produk.

2) Meningkatkan promosi dengan strategi free gift seperti "beli 12 bungkus gratis piring" pada event-event tertentu untuk menarik konsumen.

3) Mengenalkan spesifikasi dan keunggulan produk keripik buah "Mekar Sari" yang lebih detail di media sosial agar konsumen dapat membeli produk sesuai dengan kebutuhan spesifikasi yang diinginkan.

\section{DAFTAR PUSTAKA}

Aldy Rochmat, Purnomo. 2016. Analisis Statistik Ekonomi dan Bisnis dengan SPSS. Yogyakarta: Fadilatama

Amstrong dan Kotler. 2001. Prinsip-prinsip pemasaran, Edisi Keduabelas, Jilid 1. Jakarta: Erlangga.

Amstrong dan Kotler, 1999. Prinsip-Prinsip Pemasaran, Edisi Delapan, Jakarta: Penerbit Erlangga

Ghozali, Imam. 2011. "Aplikasi Analisis Multivariate Dengan Program SPSS”. Semarang: Badan Penerbit Universitas Diponegoro.

J. Supranto M. A, 2000. Statistik Teori dan Aplikasi Jilid 1, Edisi Keenam. Erlangga, Jakarta.

Sevilla, G Consuelo dkk. 1993. Pengantar metode Pennelitian. Jakarta: UIPRESS

Sugiyono. 2008. Metode Penelitian Kuantitatif Kualitatif dan R\&D. Bandung : ALFABETA

2014. Metode Penelitian Pendidikan Pendekatan Kuantitatif, Kualitatif, dan R\&D. Bandung: Alfabeta . 2015. Metode Penelitian Kombinasi (Mix Methods). Bandung: Alfabeta. 